\title{
A family-oriented treatment program for youths with ketamine abuse and their caregivers: a pilot study in Taiwan
}

\author{
Liang-Jen Wang' \\ Shing-Fang Lu' \\ Wen-Jiun Chou' \\ Mian-Yoon Chong ${ }^{2}$ \\ Yao-Hsing Wang' \\ Yu-Lian Hsieh' \\ Yi-Hsuan Lee' \\ Ching Chen ${ }^{2}$
}

'Department of Child and Adolescent Psychiatry, ${ }^{2}$ Department of Psychiatry, Kaohsiung Chang Gung Memorial Hospital and Chang Gung University College of Medicine, Kaohsiung, Taiwan

This article was published in the following Dove Press journal:

Neuropsychiatric Disease and Treatment

31 July 2015

Number of times this article has been viewed

Objective: The abuse of ketamine by youths has grown into a serious public health issue However, a reliable and efficient treatment has still not been found for youths who abuse ketamine. This pilot study investigated the effects of a family-oriented treatment program for ketamine-using youths and their caregivers.

Methods: To carry out this study, 42 youths with ketamine use (mean age $16.6 \pm 1.1$ years) who were referred to take part in a 10 -week treatment program based on motivational enhancement principles were selected, as were their principal caregivers (mean age $46.4 \pm 7.1$ years), who were similarly referred to take part in a 10 -week training program for parenting skills. The study had the youths complete the Chinese Craving Beliefs Questionnaire, the Adolescents' Behavior problem Scale, and the Family APGAR both immediately before and after the program. Likewise, the youths' caregivers completed the Family APGAR, the 12-item version of the Chinese Health Questionnaire, and the Parenting Stress Index.

Results: Of the 42 youth-caregiver pairs that took part in this study, 37 (88\%) completed the 10 -week program and both sets of assessments. After the treatment, the participating youths' substance cravings declined $(t=3.88, P<0.001)$, while family function, as perceived by the participating caregivers, significantly increased $(t=2.22, P=0.033)$. The improvement in caregivers' perceptions of family function were positively related to the improvement of the caregivers' health status ( $r=-0.36, P=0.022$ ).

Conclusion: According to its results, this pilot study submits that family-oriented treatment programs may be considered a potentially effective treatment option for youths who abuse ketamine. Additional studies with larger sample sizes, as well as longer follow-up periods, are necessary to verify whether this type of treatment also prevents youths using ketamine from relapsing.

Keywords: substance abuse, psychotherapy, family, juvenile delinquency

\section{Introduction}

Abuse of a number of substances by youths has been a serious public health issue for many years. ${ }^{1}$ Among such concerns, ketamine, an anesthetic and analgesic with hallucinogenic effects developed in the $1960 \mathrm{~s},{ }^{2}$ has recently grown into one of the most popular recreational drugs among teenagers in Taiwan ${ }^{3,4}$ and around the world. ${ }^{5}$ Chronic ketamine abuse has both physical and psychological risks, including ulcerative cystitis, kidney and gastrointestinal dysfunction, cognitive impairment, psychosis, depression, and psychological cravings. ${ }^{6,7}$ Ending ketamine abuse and providing effective treatment options for youths is thus vital to reducing its related illnesses and social burden. ${ }^{8}$ In recent years, research into the efficacy of drug abuse treatment for youths has achieved some great results. ${ }^{9}$ However, a reliable and effective pharmacological or psychosocial approach target for ketamine users has not yet been found. 
Over the past 10 years, motivational enhancement therapy has become increasingly popular among therapeutic approaches for drug-addicted youths. ${ }^{10}$ Motivational treatment programs provide a nonconfrontational environment to help youths explore the different aspects of their drug use patterns and encourage them to actively engage in treatment to ultimately stop their drug use. Group therapy can be used when attempting motivational enhancement intervention, which can start showing results quickly (as early as from 6 to 16 weeks). ${ }^{11,12}$ The evidence showing the benefits of motivational enhancement therapy for youths abusing substances has been compelling. ${ }^{13}$ However, the effect of motivational treatment programs on youths using ketamine has yet to be positively determined. Furthermore, youths who experience a poor parent-child relationship or poor family function may belong to a group at high risk for substance abuse and potential relapse. ${ }^{14-16}$ To improve family function, an effective treatment program for youths with substance abuse must also have a parenting program for the caregivers of such youths. ${ }^{17,18}$ Therefore, a family-oriented treatment program that has been adapted for ketamine-using youths may be considered as an effective treatment in the future.

According to the Controlled Drugs Act and Juvenile Accident Act in Taiwan, ${ }^{19}$ ketamine is a Schedule 3 illicit drug, and its use by youths is generally considered juvenile delinquency. Youths found to be using ketamine may be sentenced to probation, receive reformatory education, or undergo detoxification, but no standardized treatment for youths using ketamine has yet been determined in Taiwan. Therefore, since 2013, Taiwan Kaohsiung Juvenile and Family Court and Kaohsiung Chang Gung Memorial Hospital have been cooperating on a specific treatment program that targets both ketamine-using juveniles and their caregivers. The court act requires that underage individuals arrested for ketamine use undergo a treatment program in a hospital.

This study examined a group psychotherapy program for ketamine-using juveniles that was based on motivational enhancement principles ${ }^{20}$ and that included weekly meetings with youths for 10 weeks as well as 10 weekly sessions of parental skill training ${ }^{21,22}$ for the youths' caregivers. This pilot study aimed at investigating the effect of this familyoriented treatment program, on youths using ketamine and their caregivers.

\section{Methods}

\section{Study participants}

This study received approval from the Institutional Review Board at Chang Gung Memorial Hospital. The participants in this study included 42 ketamine-using youths, whose ages ranged from 12 to 18 , and their primary caregivers, all recruited between July 2013 and December 2014. The youths participated in this study were referred from the Taiwan Kaohsiung Juvenile and Family Court, and were required to participate in a weekly ten-session outpatient treatment program for substance abuse at Kaohsiung Chang Gung Memorial Hospital. Likewise, these youths' caregivers were referred to take part in a weekly ten-session outpatient training program for parenting skills. Both programs were held at the same time at Kaohsiung Chang Gung Memorial Hospital. Each participant provided written informed consent to participate in this study. The researchers emphasized to the participants and their caregivers that their decision to participate or not in this study would not affect their legal status and that all personal information provided would be kept strictly confidential.

\section{Motivational enhancement psychotherapy program for youths}

The participating youths received ten sessions, on a weekly basis, of a group-relapse prevention program centered on motivational enhancement ideas and led by two of the hospital's experienced psychologists. Each session included approximately eight participants and lasted for 120 minutes with a 10-minute break. The aim of the sessions was to evoke the youths' motivation for change by determining their reasons for using, reasons for abstaining, concerns they might have about ketamine use, and how they saw illicit drugs fitting into their life at the moment and long term. The psychologists developed a rapport with the participants and gained an understanding of how illicit drugs fit into their lives. The main technique used during the sessions was feedback, using reflection and questioning to prompt self-motivational statements. The treatment program focused on identifying situations that put youths at high risk for substance abuse, as well as on improving their motivation for abstinence and their coping strategies to prevent relapse.

\section{Parenting skills training program for caregivers}

The parenting skills training program also consisted of ten weekly 120 -minute sessions, which were handled by two senior consulting psychologists assigned from the court. The therapists first shared common legal knowledge to ease caregivers' worry and helplessness. Then, the therapists handled the caregivers' emotional reactions, such as shock, anger, and frustration, toward their teens' substance use. Caregivers assisted them in examining their current relationship with their teenagers, as well as the techniques they used to influence them. The therapists guided the participants to determine their negative family interaction patterns so that they could 
change them and thus, the everyday family environment. Furthermore, the therapists provided these caregivers with new methods to reach out to their teenagers and other methods to help teenagers address the issues separating them in developmentally nonnormative ways from their caregivers. The aim of this training program was to teach ketamine-using youths' caregivers more effective skills for coping with the problems resulting from their youths' substance abuse.

\section{Study procedures and measures}

Once participants and their caregivers gave their informed consent, they were interviewed in person to collect information regarding their sociodemographic characteristics. The ketamine-using youths were asked to fill out the Chinese Craving Beliefs Questionnaire (CCBQ), the Adolescents' Behavior-problem Scale (ABS), and the Family APGAR at the first session and the last session of treatment (10 weeks later). The youths' caregivers were asked to fill out the Family APGAR, the 12-item version of the Chinese Health questionnaire (CHQ-12), and the Chinese version of the Parenting Stress Index (PSI) at the first session as well as at the last session of treatment.

\section{CCBQ}

The CCBQ was adapted from the Craving Beliefs Questionnaire (CBQ) developed by Wright. ${ }^{23}$ This questionnaire measures beliefs about and understanding of substance cravings and consists of ten items answered with a four-point Likert scale ranging from totally disagree (1) to totally agree (4). Higher total scores represent greater levels of substance craving. The CCBQ has acceptable reliability and validity and is appropriate for use as a research instrument in assessing substance craving beliefs. ${ }^{24}$

\section{ABS}

The ABS is a self-administered questionnaire that measures the emotional disturbance of youths. The ABS contains 50 items, each of which is answered with a six-point Likert scale. The ABS consists of the following five categories dealing with self-awareness, development of body and mind, school life, interpersonal relationships, and family life; it then provides a composite score. This questionnaire has good reliability and validity. ${ }^{25}$

\section{Family APGAR}

The Family APGAR has been widely applied to measure families' well-being. ${ }^{26}$ It deals with the following five items: degree of adaptation, partnership, growth, affection, and resolution in the family. Each item was answered using a three-point Likert scale that ranged from 0 (low satisfaction) to 2 (high satisfaction). The total scores ranged from 0 to 10 , with a higher score representing better family function. The Chinese version of this questionnaire has adequate internal reliability and validity. ${ }^{27}$

\section{CHQ- 12}

The CHQ-12, a 12-item self-reporting questionnaire, was a modified version of the General Health Questionnaire. ${ }^{28}$ This instrument has been widely applied in studies to identify subjects in primary care as well as those in the community setting who have minor psychiatric disorders. A four-point Likert scale, ranging from 0 (not at all) to 3 (more than usual), was provided as the response format to analyze conditions within the preceding 2 weeks (giving a score range of 12-36). Higher scores represented worse health conditions. This questionnaire has good reliability and validity. ${ }^{29}$

\section{PSI}

The PSI was a standardized Chinese version of the original 101-item questionnaire, which measures elements of parental functioning. ${ }^{30}$ The PSI Parent Domain Scale contains 54 items and is made up of seven subscales. The PSI Child Domain Scale contains 47 items and has six subscales. The parent and child domains are added together to yield a total score and a derived raw-to-percentile score. The youths' caregivers rated their level of agreement with the items on a five-point Likert scale. Higher scores indicate a greater level of parenting stress. ${ }^{31}$

\section{Statistical analysis}

Data were analyzed using the statistical software package SPSS, version 16.0 (SPSS Inc., Chicago, IL, USA). Variables were offered as either mean ( \pm standard deviation) or frequency (\%). This study used a paired $t$-test to examine any changes in the measures for either the youths or their caregivers throughout the 10 -week treatment program. The researchers performed the Pearson correlation to analyze the relationships between the changes in both the youths' measures and the caregivers' measures. A two-tailed $P$-value $<0.05$ was considered statistically significant.

\section{Results}

The mean age of the 42 ketamine-using youths was $16.6 \pm 1.1$ years, with $14(33.3 \%)$ of them being girls (Table 1). Regarding the school status or social status of these youths, $18(42.9 \%)$ were in a residence; $15(35.7 \%)$ had been suspended or dropped out from school; and nine $(21.4 \%)$ were employed. With regard to family status, 19 (45.2\%) lived in 
Table I Characteristics of youths with ketamine abuse $(\mathrm{N}=42)$ and their caregivers $(\mathrm{N}=42)$ participating in a weekly 10 -week outpatient treatment program

\begin{tabular}{|c|c|c|}
\hline & Mean or $\mathbf{N}$ & SD or $\%$ \\
\hline \multicolumn{3}{|c|}{ Characteristics of the youths } \\
\hline Age (years) & 16.6 & I.I \\
\hline Sex (female/male) & $14 / 28$ & $33.3 / 66.7$ \\
\hline \multicolumn{3}{|c|}{ School status or social status } \\
\hline Residence & 18 & 42.9 \\
\hline Suspension or dropout & 15 & 35.7 \\
\hline Employed & 9 & 21.4 \\
\hline \multicolumn{3}{|l|}{ Family status } \\
\hline Two-parent families & 19 & 45.2 \\
\hline Single-parent families & 22 & 52.4 \\
\hline Adoptive family & I & 2.4 \\
\hline \multicolumn{3}{|c|}{ Characteristics of caregivers } \\
\hline Age (years) & 46.4 & 7.1 \\
\hline Sex (female/male) & $23 / 19$ & $51.8 / 45.2$ \\
\hline \multicolumn{3}{|l|}{ Relationship to youths } \\
\hline Mother & 19 & 45.2 \\
\hline Father & 17 & 40.5 \\
\hline Other & 6 & 14.3 \\
\hline
\end{tabular}

Abbreviation: SD, standard deviation.

two-parent families; 22 (52.4\%) lived in single-parent families; and one (2.4\%) lived in an adoptive family. Of the 42 caregivers that participated in the treatment program (mean age $46.4 \pm 7.1$ years), 19 (45.2\%) were mothers of one of the youths; 17 (40.5\%) were their fathers; and six (14.3\%) were other relatives of the youths.

Of the 42 youth-caregiver pairs that participated in this study, 37 (88\%) completed the 10-week treatment program and assessment. Table 2 displays the changes in the youths' measures and those of their caregivers from the baseline to the end point of the follow up. During the 10-week familyoriented programs, the CCBQ scores of the youths decreased significantly $(t=3.88, P<0.001)$, while the Family APGAR scores of the caregivers significantly increased $(t=2.22$, $P=0.033)$. However, the ABS scores, Family APGAR scores of the youths, and CHQ scores and the PSI scores of the caregivers did not show significant changes over the 10 -week period $(P>0.05)$.

Table 3 shows the summary of the relationship changes between the youths' measures and caregivers' measures once the 10-week treatment program had been completed. The changes in the Family APGAR scores of the caregivers had a negative relationship with the changes of their CHQ scores $(r=-0.36, P=0.022)$. The changes in the PSI-parent domain had a positive relationship with the changes in the PSI-child domain ( $r=0.37, P=0.020$ ). However, the changes in the youths' measures did not significantly relate to the changes in any of the caregivers' measures $(P>0.05)$.

\section{Discussion}

This pilot study is the leader in providing evidence of the results of a family-oriented group treatment program addressing both ketamine-using youths and their caregivers. During the 10-week group motivational enhancement psychotherapy, the youths' substance craving beliefs (the primary result of this study) significantly declined. While specific ketamine withdrawal symptoms have not yet been pinpointed, psychological cravings seem to be among the key problems in frequent ketamine users. ${ }^{6,32}$ Wang et $\mathrm{al}^{33}$ reported that patients with ketamine-associated bladder dysfunction had a high relapse rate $(70 \%)$ of ketamine abuse during a 1-year follow-up period. This finding implies that breaking the drug addiction cycle in ketamine users is not easy. Although the youths' substance craving beliefs diminished after the treatment in this study, further investigation into whether the said treatment prevents those youths from ketamine use relapse is necessary in the future. It is also worth mentioning that the youths' emotional disturbance and family function perceived by the participating youths (secondary results) did not significantly change during the study period.

Table 2 Measures of the youths and their caregivers at the baseline and 10 weeks later, after a family-oriented outpatient treatment program for youths who abuse ketamine $(\mathrm{N}=37)$

\begin{tabular}{lllll}
\hline & Baseline & I0 weeks later & t-value & P-value \\
\hline Measures of youths & & & & \\
Chinese Craving Beliefs Questionnaire & $8.5 \pm 7.8$ & $5.9 \pm 5.4$ & 3.88 & $0.00 I^{* * *}$ \\
Adolescents' Behavior-problem Scale & $40.2 \pm 9.6$ & $38.8 \pm 9.4$ & 1.00 & 0.326 \\
Family APGAR-Adolescents & $6.8 \pm 2.5$ & $7.3 \pm 2.7$ & -1.28 & 0.207 \\
Measures of youths' caregivers & & & -2.22 & $0.033^{*}$ \\
Family APGAR-Caregivers & $4.5 \pm 3.4$ & $6.0 \pm 2.7$ & 0.95 & 0.350 \\
Chinese Health Questionnaire & $4.2 \pm 4.1$ & $3.7 \pm 3.5$ & 1.00 & 0.325 \\
Parenting Stress Index-Parent domain & $138.7 \pm 24.9$ & $135.5 \pm 24.4$ & 1.41 & 0.167 \\
Parenting Stress Index-Child domain & $22.1 \pm 5.2$ & $21.1 \pm 5.1$ & & \\
\hline
\end{tabular}

Notes: $* P<0.05 ; * * * P<0.001$. 
Table 3 Correlation of changes in youths' measures and changes in caregivers' measures after the 10-week treatment program for ketamine-abusing youths

\begin{tabular}{|c|c|c|c|c|c|c|c|}
\hline & ССВQ & ABS & APGAR-Y & APGAR-C & CHQ-I 2 & PSI-P & PSI-C \\
\hline Chinese Craving Beliefs Questionnaire & - & & & & - & & \\
\hline Adolescents' Behavior-problem Scale & -0.03 & - & & & & & \\
\hline Family APGAR-Youths & -0.05 & 0.06 & - & & & & \\
\hline Family APGAR-Caregivers & 0.20 & 0.19 & -0.10 & - & & & \\
\hline Chinese Health Questionnaire & 0.11 & -0.06 & -0.14 & $-0.36^{*}$ & - & & \\
\hline Parenting Stress Index-Parent domain & 0.22 & -0.18 & -0.03 & 0.28 & 0.30 & - & \\
\hline Parenting Stress Index-Child domain & 0.13 & 0.12 & -0.24 & -0.12 & 0.22 & $0.37^{*}$ & - \\
\hline
\end{tabular}

Notes: Data is expressed using Pearson's correlation coefficients $(r)$; $P<0.05$. The blank spaces in the table represent that the repeated statistic values in the correlation matrix that do not need to be shown.

Abbreviations: ABS, Adolescents' Behavior-problem Scale; APGAR-C, Family APGAR-Caregivers; APGAR-Y, Family APGAR-Youths; CCBQ, Chinese Craving Beliefs Questionnaire; CHQ-12, I2-item version of the Chinese Health Questionnaire; PSI-C, Parenting Stress Index-Child domain; PSI-P, Parenting Stress Index-Parent domain.

One possible explanation is that the main goal of motivational enhancement psychotherapy is to encourage youths to stop using drugs and is not concerned with other issues; therefore, such treatment may not be beneficial for helping deal with the youths' emotional disturbance and family function. However, these negative findings may be related to the small sample size and low statistical power of the study.

After the group parenting skills training, family wellbeing perceived by the youths' caregivers was significantly improved. The program for youths' caregivers emphasized reforming their relationship with their teenagers, as well as their strategies for getting along with their teens. The therapists worked with the caregivers to increase their engagement in the treatment of the youths' and their motivation for change, as well as to improve their parenting, communication, and problem-solving skills. The interaction between family members might thus be improved and may be further linked to better family function. ${ }^{14,15}$ However, the health status and parental stress of the youths' caregivers did not change during the course of the treatment program. The youths' caregivers may suffer from helplessness and frustration as a consequence of their teens' substance abuse. The study findings suggest that our treatment program for caregivers could be altered to provide more psychological support and strategies for coping with stress, in the future.

After the 10-week program for parenting skills training, the changes in the Family APGAR scores for caregivers related negatively to the changes of their CHQ scores. This finding shows that a greater improvement in the caregivers' family function was related to a better level of their health. Furthermore, changes in the PSI-parent domain were positively related to changes in the PSI-child domain. This result suggests that the caregivers' perception of the impact of the child's temperamental characteristics on the parent-child system was associated with the stress perceived by the caregivers themselves. ${ }^{30}$
However, changes in the youths' measures did not correlate with changes in any of the caregivers' measures. Since this comprehensive treatment approach addresses the youths' substance abuse and worked within the family system, further communication between adolescents and their caregivers, or joint group sessions may be included in a future treatment program. Furthermore, having the youths and their caregivers share their experiences and how they benefited from the treatment might help them to better understand each other.

This study had several limitations. First, being a pilot study, it had a small sample size. This characteristic reduced the study's ability to detect the potential benefits of the treatment program and limited its capability to identify outcome-associated factors. Therefore, some negative findings in this study may only be the result of inadequate statistical power. Second, this study was administered in a noncomparative, nonrandomized, and open-label manner, so changes in the youths' and caregivers' measures could not to be compared with those without treatment. Furthermore, even though the court required all the minor individuals who were arrested for ketamine use to attend the treatment program, some may have been unavailable for participation (ie, those who had already been sentenced to jail or whose caregivers were unapproachable). This potential selection bias could affect the generality of the study findings. Third, all measures in this study were self-administered; therefore, they may have been influenced by socially desirable responses and motivation bias. The probable underreporting of drug-craving beliefs and emotional disturbance among participants may also have influenced the results. Finally, this research did not address posttreatment results regarding ketamine-use relapses; thus, the treatment program's effectiveness with regard to relapse prevention is still unknown.

This pilot study reveals the potential effects of a 10 -week treatment program for ketamine-using juveniles and their caregivers in Taiwan. Throughout the motivational program, 
the youths' substance cravings declined significantly. Once the parenting skills training was completed, family wellbeing perceived by the youths' caregivers significantly improved. The study findings suggest that a family-oriented treatment program may be considered as a promising effective treatment option for ketamine-using youths. However, in the future, further studies with a larger sample size and a longer follow-up period are required, to determine whether this type of treatment program prevents adolescents from ketamine use relapse.

\section{Acknowledgments}

The authors would like to thank Tong-Ning Tsai, MingHsiung Liu, Yung-Hsuan Lee, and the staff of Taiwan Kaohsiung Juvenile and Family Court, as well as all the patients who participated in this study. This study was funded by a grant from Chang Gung Memorial Hospital (grant number CMRPG8C1091).

\section{Disclosure}

The authors report no conflicts of interest in this work.

\section{References}

1. Merikangas KR, McClair VL. Epidemiology of substance use disorders. Hum Genet. 2012;131(6):779-789.

2. Bokor G, Anderson PD. Ketamine: an update on its abuse. J Pharm Pract. 2014;26(6):582-586.

3. Chen WJ, Fu TC, Ting TT, et al. Use of ecstasy and other psychoactive substances among school-attending adolescents in Taiwan: national surveys 2004-2006. BMC Public Health. 2009;9:27.

4. Lee KH, Yeh YC, Yang PC, et al. Individual and peer factors associated with ketamine use among adolescents in Taiwan. Eur Child Adolesc Psychiatry. 2012;21(10):553-558.

5. Li JH, Vicknasingam B, Cheung YW, et al. To use or not to use: an update on licit and illicit ketamine use. Subst Abuse Rehabil. 2011; 2:11-20.

6. Morgan CJ, Curran HV; Independent Scientific Committee on Drugs. Ketamine use: a review. Addiction. 2012;107(1):27-38.

7. Xu J, Lei H. Ketamine-an update on its clinical uses and abuses. CNS Neurosci Ther. 2014;20(12):1015-1020.

8. Arain M, Haque M, Johal L, et al. Maturation of the adolescent brain. Neuropsychiatr Dis Treat. 2013;9:449-461.

9. Winters KC, Tanner-Smith EE, Bresani E, Meyers K. Current advances in the treatment of adolescent drug use. Adolesc Health Med Ther. 2014; 5:199-210.

10. Bukstein OG, Horner MS. Management of the adolescent with substance use disorders and comorbid psychopathology. Child Adolesc Psychiatr Clin N Am. 2010;19(3):609-623.

11. Peterson PL, Baer JS, Wells EA, Ginzler JA, Garrett SB. Short-term effects of a brief motivational intervention to reduce alcohol and drug risk among homeless adolescents. Psychol Addict Behav. 2006; 20(3):254-264.

12. Ryan SR, Stanger C, Thostenson J, Whitmore JJ, Budney AJ. The impact of disruptive behavior disorder on substance use treatment outcome in adolescents. J Subst Abuse Treat. 2013;44(5):506-514.

13. Tevyaw TO, Monti PM. Motivational enhancement and other brief interventions for adolescent substance abuse: foundations, applications and evaluations. Addiction. 2004;99 Suppl 2:S63-S75.
14. Kamon JL, Stanger C, Budney AJ, Dumenci L. Relations between parent and adolescent problems among adolescents presenting for familybased marijuana abuse treatment. Drug Alcohol Depend. 2006;85(3): 244-254.

15. Hummel A, Shelton KH, Heron J, Moore L, van den Bree MB. A systematic review of the relationships between family functioning, pubertal timing and adolescent substance use. Addiction. 2013;108(3): 487-496.

16. Calafat A, García F, Juan M, Becoña E, Fernández-Hermida JR. Which parenting style is more protective against adolescent substance use? Evidence within the European context. Drug Alcohol Depend. 2014;138:185-192.

17. Galanter M, Glickman L, Singer D. An overview of outpatient treatment of adolescent substance abuse. Subst Abus. 2007;28(2):51-58.

18. Tanner-Smith EE, Wilson SJ, Lipsey MW. The comparative effectiveness of outpatient treatment for adolescent substance abuse: a metaanalysis. J Subst Abuse Treat. 2013;44(2):145-158.

19. Narcotics Hazard Prevention Act [webpage on the Internet]. Laws \& Regulations Database of The Republic of China; 2015 [cited April 2, 2015]. Available from: http://law.moj.gov.tw/Eng/LawClass/ LawContent.aspx?PCODE=C0000008. Accessed June 17, 2015.

20. Walker DD, Stephens R, Roffman R, et al. Randomized controlled trial of motivational enhancement therapy with nontreatment-seeking adolescent cannabis users: a further test of the teen marijuana check-up. Psychol Addict Behav. 2011;25(3):474-484.

21. McGillicuddy NB, Rychtarik RG, Duquette JA, Morsheimer ET. Development of a skill training program for parents of substance-abusing adolescents. $J$ Subst Abuse Treat. 2001;20(1):59-68.

22. Liddle HA, Rowe CL, Dakof GA, Ungaro RA, Henderson CE. Early intervention for adolescent substance abuse: pretreatment to posttreatment outcomes of a randomized clinical trial comparing multidimensional family therapy and peer group treatment. J Psychoactive Drugs. 2004;36(1):49-63.

23. Beck AT, Wright FD, Newman CF, Liese BS, eds. Cognitive Therapy of Substance Abuse. NY: The Guilford Press; 1993.

24. Chang CW, Huang CW, Wu WH, et al. Psychometric properties of the Chinese craving beliefs questionnaire for heroin abusers in methadone treatment. BMC Psychiatry. 2011;11:39.

25. Hagborg WJ. Prevalence and correlates of self-reported depressive mood among seriously emotionally disturbed adolescents. Psychol Rep. 1992;70(1):23-26.

26. Smilkstein G, Ashworth C, Montano D. Validity and reliability of the family APGAR as a test of family function. J Fam Pract. 1982; 15(2):303-311.

27. Chau TT, Hsiao TM, Huang CT, Liu HW. [A preliminary study of family Apgar index in the Chinese]. Gaoxiong Yi Xue Ke Xue Za Zhi. 1991;7(1): 27-31. Chinese.

28. Chong MY, Wilkinson G. Validation of 30- and 12-item versions of the Chinese Health Questionnaire (CHQ) in patients admitted for general health screening. Psychol Med. 1989;19(2):495-505.

29. Cheng TA, Williams P. The design and development of a screening questionnaire (CHQ) for use in community studies of mental disorders in Taiwan. Psychol Med. 1986;16(2):415-422.

30. Yeh CH, Chen ML, Li W, Chuang HL. The Chinese version of the Parenting Stress Index: a psychometric study. Acta Paediatr. 2001;90(12): 1470-1477.

31. Yang P, Jong YJ, Hsu HY, Tsai JH. Psychiatric features and parenting stress profiles of subtypes of attention-deficit/hyperactivity disorder: results from a clinically referred Taiwanese sample. J Dev Behav Pediatr. 2007;28(5):369-375.

32. Chen WY, Huang MC, Lin SK. Gender differences in subjective discontinuation symptoms associated with ketamine use. Subst Abuse Treat Prev Policy. 2014;9:39.

33. Wang YC, Chen SK, Lin CM. Breaking the drug addiction cycle is not easy in ketamine abusers. Int J Urol. 2010;17(5):496; author reply 497. 


\section{Publish your work in this journal}

Neuropsychiatric Disease and Treatment is an international, peerreviewed journal of clinical therapeutics and pharmacology focusing on concise rapid reporting of clinical or pre-clinical studies on a range of neuropsychiatric and neurological disorders. This journal is indexed on PubMed Central, the 'PsycINFO' database and CAS, and is the official journal of The International Neuropsychiatric Association (INA). The manuscript management system is completely online and includes a very quick and fair peer-review system, which is all easy to use. Visit http://www.dovepress.com/testimonials.php to read real quotes from published authors.

\footnotetext{
Submit your manuscript here: http://www.dovepress.com/neuropsychiatric-disease-and-treatment-journal
} 